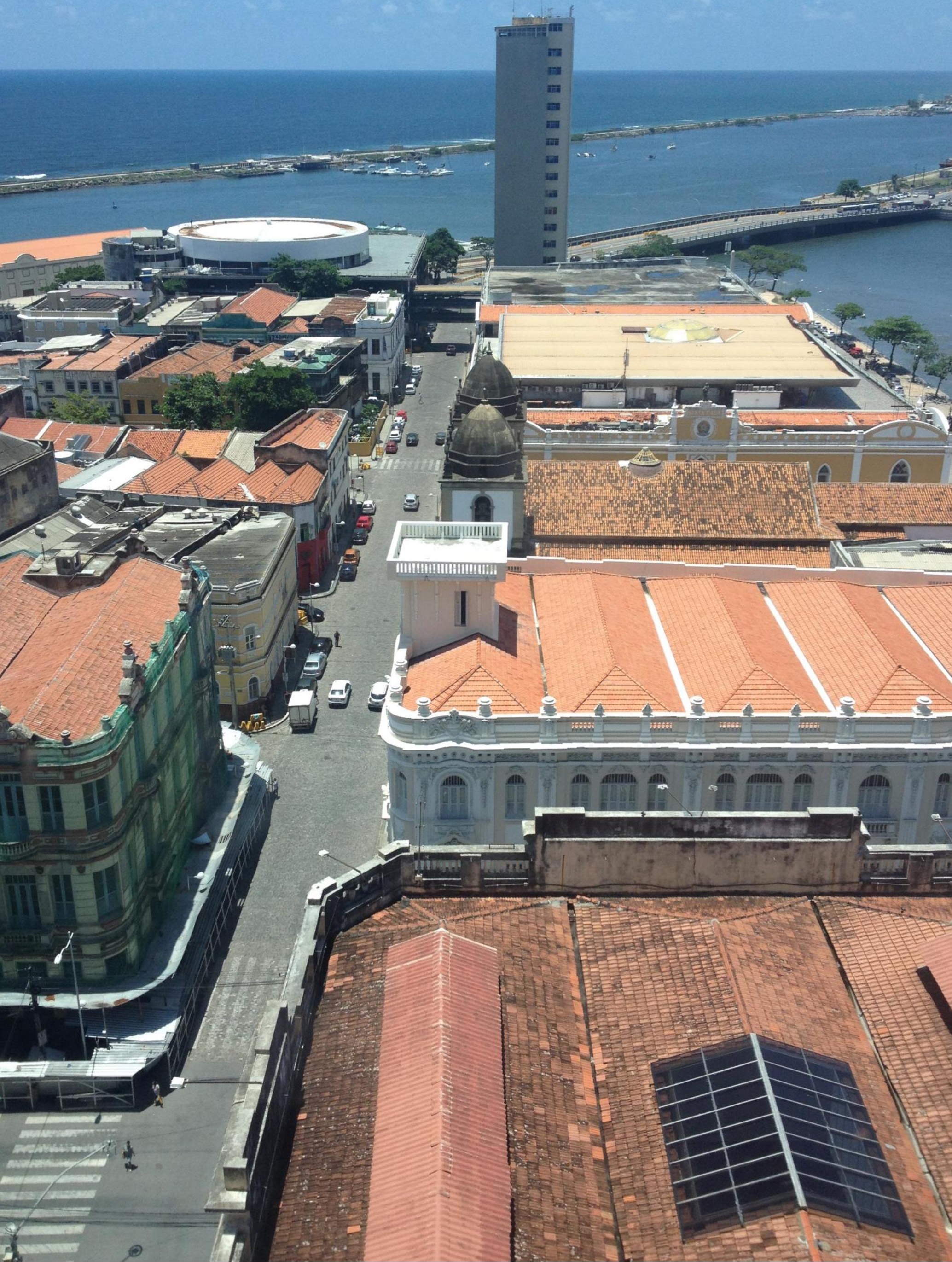




\title{
APOIO DE RESIDENTES AO DESENVOLVIMENTO DO TURISMO NA CIDADE DE FLORÂNIA, RIO GRANDE DO NORTE, BRASIL
}

\author{
Apoyo de residentes al desarrollo del Turismo en la ciudad de Florania, Rio Grande do Norte, \\ Brasil
}

Support of residents to the development of Tourism in the city of Florânia, Rio Grande do Norte, Brazil

\author{
Helayne Claedna de Souza Silva ${ }^{1}$ \\ Marcelo Chiarelli Milito ${ }^{2}$ \\ Ana Catarina Alves Coutinho ${ }^{3}$ \\ Mayara Ferreira de Farias ${ }^{4}$
}

Resumo: O turismo é considerado uma atividade econômica que pode contribuir para o desenvolvimento de uma localidade. Para tanto, é importante levar em consideração os impactos gerados pela atividade, assim como analisar de que forma os residentes percebem o desenvolvimento do turismo. $O$ objetivo desse trabalho é analisar o apoio dos residentes de Florânia/RN sobre o desenvolvimento turístico no município. A pesquisa é de caráter descritivo e utiliza a abordagem quantitativa baseada no método hipotético-dedutivo. Os resultados evidenciam que os residentes da cidade são influenciados em apoiar o desenvolvimento do turismo se considerar os benefícios para além dos fatores econômicos, apoiando e confiando nos atores governamentais e no empresariado local. Custos advindos da atividade turística devem ser minimizados para obter um maior apoio dos residentes.

Palavras-Chave: Apoio do residente; Turismo; Impactos; Florânia/RN.

Resumen: El turismo se considera una actividad económica que puede contribuir al desarrollo de una localidad. Para ello, es importante tener en cuenta los impactos generados por la actividad, así como analizar de qué forma la población residente percibe el desarrollo del turismo. El objetivo de este trabajo es analizar el apoyo de los residentes de Florania/RN sobre el desarrollo turístico en el municipio. La investigación es de carácter descriptivo y utiliza el abordaje cuantitativo basado en el método hipotético-deductivo. Los resultados evidencian que los residentes de la ciudad son influenciados en apoyar el desarrollo del turismo si se consideran los beneficios más allá de los factores económicos, apoyando y confiando en los actores gubernamentales y en el empresariado. Los costos provenientes de la actividad turística deben ser minimizados para obtener un mayor apoyo de los residentes.

Palabras clave: Apoyo del residente; turismo; impactos; Florânia/RN.

Abstract: Tourism is considered an economic activity that can contribute to the development of a locality. Therefore, it is important to take into account the impacts generated by the activity, as well as to analyze how the resident population perceives the development of tourism. The objective of this work is to analyze the support of the residents of Florânia/RN on the tourist development in the municipality. The research is descriptive and uses the quantitative approach based on the hypothetical-deductive method. The results show that the city's residents are influenced in supporting tourism development if consider the benefits beyond economic factors, by supporting and relying on government actors and entrepreneurs. Costs arising from tourist activity should be minimized to obtain greater support from residents.

Keywords: Resident support; Tourism; Impacts; Florânia/RN.

\footnotetext{
${ }^{1}$ Graduada em Turismo. Universidade Federal do Rio Grande do Norte. E-mail: helayneclaedna@gmail.com

2 Doutorando e Mestre em Turismo pelo PPGTUR/UFRN. E-mail: marcelomilito@yahoo.com.br

${ }^{3}$ Mestre em Turismo e Doutoranda em Turismo (PPGTUR). Docente na Universidade Federal do Maranhão/Campus São Bernardo (UFMA) e Doutoranda na Universidade Federal do Rio Grande do Norte (UFRN). E-mail: coutinho.catarina1@gmail.com

${ }^{4}$ Doutoranda e Mestre em Turismo pela UFRN (PPGTUR). Especialista em Gestão Pública Municipal pela UFPB. Especialista em História e Cultura Afro-Brasileira e Africana/NCCE (UFRN). Especialista em Política de Promoção da Igualdade Racial (UNIAFRO) pela UFERSA.. Graduada em Letras Espanhol (IFRN). Bacharel em Turismo (UFRN). Técnico em Guia de Turismo Regional pelo SENAC (Natal). E-mail: mayaraferreiradefarias@gmail.com
} 


\section{INTRODUÇÃO}

O turismo tem ganhado importância tanto no campo teórico quanto no empírico devido às diversas transformações vinculadas ao setor. Ao longo dos anos, tem se tornado uma atividade econômica de grande expressão no mundo, desempenhando um papel importante devido a sua contribuição na movimentação econômica e consequentemente na providência de melhorias para a comunidade receptora através da geração de emprego e renda, dotação de infraestrutura básica, turística e de apoio, dentre outros fatores. Paralelamente a estes aspectos, o turismo também é visto como uma atividade social capaz de potencializar aspectos culturais, ambientais, sociais e identitários de uma localidade.

Dentre os vários efeitos do turismo, existe uma atenção sobre os impactos causados nas comunidades receptoras, por ser uma atividade que influencia e também é influenciada pelos lugares (Leiper, 1979). Por isto, quando não planejada pode ocasionar impactos negativos e custos aos destinos.

Nesta perspectiva, alguns estudos tais como os propostos por Silva e Marques Júnior (2016), Milito, Marques-Júnior e Alexandre (2015), Nunkoo e Ramkissoon (2012) e Gursoy e Rutherford (2004) apontam que a percepção dos benefícios e dos custos do turismo pela comunidade residente, constitui um fator que pode influenciar o apoio no desenvolvimento do turismo. Ademais, a informação de apoio (ou não) pode ser um instrumento de gerenciamento das localidades e ajustamento das ações.

Assim, constitui-se como objetivo geral desse artigo: analisar o apoio dos residentes em relação ao desenvolvimento do turismo em Florânia, Rio Grande do Norte, Brasil, numa perspectiva do desenvolvimento local. A prossecução deste objetivo conduziu a identificação do perfil sociodemográfico da amostra dos residentes pesquisados e a identificação da percepção dos residentes sobre os benefícios do turismo, dos custos e do poder de influência no desenvolvimento da atividade e, por fim, de como estes fatores se relacionam com o apoio ao desenvolvimento do turismo.

A cidade de Florânia/RN está em uma região onde existem atrativos turísticos relacionados ao segmento cultural, de aventura e religioso que impulsiona um pequeno fluxo turístico na localidade, sendo considerada como categoria D pela Classificação do Ministério do Turismo, que está diretamente associada a infraestrutura e fluxo turístico. Para tanto, entende-se que o primeiro passo é analisar a percepção do apoio residente em relação ao desenvolvimento do turismo.

A pesquisa é parte de uma monografia apresentada em instituição pública brasileira onde os dados foram lapidados com a possibilidade de novas análises que foram aqui apresentadas. Assim, o 
estudo pode ser um instrumento de gerenciamento do setor público e privado frente às opiniões e percepções acerca do desenvolvimento do turismo na localidade.

Ademais, é importante considerar o caráter inovador da pesquisa por não existir nenhum trabalho semelhante na localidade investigada e apenas alguns, ainda de caráter incipiente, são realizados na região. Com isso, o presente estudo torna-se relevante pela sua originalidade no campo de estudo e por se tratar de um tema que vêm sendo bastante discutido na atualidade que é a relação entre turismo e residentes.

\section{DESENVOLVIMENTO LOCAL DO TURISMO E OS IMPACTOS NA COMUNIDADE RECEPTORA}

A atividade turística vem se mostrando promissora nos últimos anos devido à capacidade de impulsionar o desenvolvimento das localidades, uma vez que abrange diversos setores da economia e, portanto, inúmeros impactos positivos e negativos na comunidade receptora. No entanto, é consenso na literatura que a atividade turística não deve ser considerada como o principal responsável pelo desenvolvimento de uma determinada localidade (Coutinho, 2016; Molina, 2003; Boyer, 2003).

Segundo Tomazzoni (2009, p. 19), "desenvolvimento econômico não significa crescimento econômico. O fato de haver crescimento econômico não é condição suficiente para o desenvolvimento humano". No entanto, inicialmente as questões de desenvolvimento foram pautadas unicamente no aspecto econômico e na diminuição das desigualdades entre as nações, em termos de renda per capita e Produto Interno Bruto (Urano et al., 2015; Moreira \& Crespo, 2012). Com isso, surgem diversas teorias que buscavam solucionar as disparidades do processo desenvolvimentista que ocorre no pós Segunda Guerra Mundial, com o foco de criticar as teorias de modernização que sobrevalorizam os aspectos econômicos.

Em meados dos anos de 1970, autores como Seers aborda o conceito de Desenvolvimento Humano, instigado pelas publicações de Silent Spring (1962) e a Conferência de Estocolmo (1972) com o foco de demonstrar a possibilidade de mobilidade da economia a partir das dinâmicas locais e, portanto, de uma maneira mais difusa para além das relações entre Estado e Mercado no desenvolvimento das nações.

Na década de 1980, surge o conceito de desenvolvimento sustentável apresentado pela comissão de Brundtland, no relatório Our Common Future (1987), reforçada pela Conferência das Nações Unidas sobre o Meio Ambiente e o Desenvolvimento, conhecida como Rio-92. As concepções de desenvolvimento sustentável foram abordadas no turismo por teóricos como Ruschmann (2010) remetendo a um modelo de desenvolvimento mais sustentável, baseado nas ações de planejamento do produto turístico. A referida autora aborda o turismo de massa como um vetor de agressões aos 
espaços naturais, devido ao número excessivo de visitantes no mesmo local em um mesmo período, e, por isso, contribui com a conservação do meio ambiente no campo do turismo e discute uma possível harmonia entre desenvolvimento da atividade e a sustentabilidade dos recursos.

Ainda neste mesmo período, emerge o conceito de desenvolvimento local, abordados por teóricos como Boisier (1996; 2000) e Barquero (2001) que defendem que o desenvolvimento se produz como um resultado de um forte processo de articulação de atores locais e variadas formas de capital intangível baseada em um marco de um projeto político que permita essa atuação das forças locais.

Para os autores supracitados, estas forças não estão restritas a população local, mas a cooperação nas relações entre Estado, Mercado e população local, considerando as especificidades do território. Nesse sentido, Barquero (2001) cita o papel do entorno inovador para o desenvolvimento das localidades, isto é, uma formação de redes de atores e sistemas produtivos locais que se inter-relacionam de forma específica em um processo de influenciar e também ser influenciado. Esses sistemas e atores competem entre si, de acordo com o autor, mas, também, mantêm relações de cooperação.

Para Boisier $(1996 ; 2000)$ o desenvolvimento de uma localidade pode ser pensado a partir da existência, articulação e manejo de seis elementos, o que ele denomina como Hexágono do Desenvolvimento, sendo a relação entre atores, instituições, cultura, procedimentos, recursos e o entorno (Coutinho, 2016).

Esta teoria influenciou de forma direta as pesquisas e a empiria no turismo, sendo difundida por teóricos como Pirillo e Cerdan (2010), Moraes, Irving e Mendonça (2018), Nunes e Menezes (2018), Tomazin e Beni (2017) e muitos outros que permitiram o surgimento modelos de planejamento turístico tendo como foco o desenvolvimento local.

Ainda como reflexo do processo de modernização e as críticas que dela emergiram, surge a concepção de Desenvolvimento como Liberdade proposto por Amartya Sen (2000), considerando a eliminação das fontes de privação como um passo para o desenvolvimento. Nesta perspectiva libertária, o desenvolvimento está centrado no agente enquanto indivíduo para moldar o seu próprio destino. O desenvolvimento, portanto, está em uma postura participativa da população que irá conduzir, de forma democrática, o desenvolvimento local, autêntico e libertário. Estes debates sofreram influência direta nas discussões do processo de desenvolvimento em turismo que são largamente difundidos.

Para fins desta pesquisa, considera o processo de desenvolvimento do turismo como aquele para além dos aspectos econômicos, aportados na teoria de Boisier (2000) e Barquero (2001) que trata sobre o desenvolvimento local; de Amartya Sen (2000) que aborda o Desenvolvimento como 
Liberdade; e de Ruschmann (2010) considerando o desenvolvimento como um tripé para a sustentabilidade.

As ações de desenvolvimento da atividade turística só podem ser pensadas em um cenário macro, uma vez que abrange várias organizações que atuam diretamente ou indiretamente no processo, através da possibilidade deste entorno inovador (Barquero, 2000). Neste sentido, torna-se, extremamente, necessário o planejamento das ações a serem desenvolvidas com o intuito de possibilitar benefícios para a comunidade receptora.

A meta de desenvolver o turismo em uma comunidade é maximizar os impactos positivos e minimizar os potenciais impactos negativos. Esses podem ser gerados no âmbito econômico, sociocultural e ambiental. Nessas concepções, percebe-se que os impactos não são ocasionados por apenas uma causa ou um problema específico, e sim, por uma diversidade de fatores que abrangem turistas, residentes e o setor empresariado. Com isso, a atividade turística deve ser realizada de forma adequada para que os recursos não sejam degradados e que se sustentem para as próximas gerações.

\section{Custos e benefícios da atividade turística}

Diversas são as discussões na literatura que abordam os custos e os benefícios da atividade turística. O que parece consenso entre os atores é que o planejamento turístico é um dos instrumentos para minimizar ou maximizar tais efeitos - sua presença ou ausência, dentre outros benefícios (Farias, 2013; Coutinho, 2016; Silva \& Marques Júnior, 2016).

Neste sentido, o planejamento deve ser realizado tendo como guarda-chuva as discussões de desenvolvimento local e os diversos impactos que a comunidade local pode sofrer com o seu advento. Estes impactos, são identificados de três tipos de acordo com a literatura no turismo, são eles: impactos econômicos, impactos socioculturais e impactos ambientais (Lage \& Milone, 2001; Swarbrooke, 2000; Beni, 2006; Lohmann \& Panosso-Netto, 2012).

Considerando o efeito econômico da atividade turística, verifica-se que tais características são ferramentas que auxilia na administração de recursos que são resultados da produção de determinados produtos ou serviços das organizações. É uma dimensão importante no processo de desenvolvimento de uma localidade, mas não deve ser o único foco. Paralelamente aos efeitos econômicos, a atividade turística também provoca mudanças nos hábitos, costumes, culturas de ambas as partes sendo discutida no turismo desde a década de 1880 a partir de pesquisadores sociológicos e antropólogos (Cohen, 1983; Smith, 1989). Estes impactos estão, diretamente, relacionados a organização social, o ritmo de vida social, a divisão social, a forma como é direcionada o advento dos turistas, os preços, empregos, dentre outros fatores. 
Por sua vez, as discussões dos impactos ambientais, também despontaram no mesmo período, através das discussões de desenvolvimento atrelado as questões ambientais. O primeiro artigo científico, por exemplo, a citar o termo turismo sustentável foi publicado em 1990 por Pigram e desde então alguns marcos da emergência do tema surgiram (Mccool et al., 2013). Com isso, as discussões sobre as questões ambientais ganharam destaque como uma atividade que impacta na localidade e pode ser maximizada através da realização desordenada.

Percebe-se, assim que a dualidade do turismo (custos e benefícios) pode ser vista de maneira mais sutil ou incisiva dependendo da forma como é implementada e desenvolvida e, com isso, a comunidade local em conjunto com o Mercado e Estado têm a responsabilidade de estabelecer como a atividade deve ser realizada em seu território (Boisier, 2000; Barquero, 2001).

No quadro 01, sintetiza-se alguns dos principais aspectos apontados na literatura sobre os custos e benefícios da atividade turística à luz da discussão realizada. Estes foram sinalizados em categorias que serão trabalhadas neste artigo e servem de subsídio para elaboração da técnica de coleta de dados.

Quadro 01. Custos e benefícios da atividade turística

\begin{tabular}{|c|c|c|}
\hline & BENEFÍCIOS & CUSTOS \\
\hline \multirow{4}{*}{$\frac{\text { go }}{2}$} & Advento de renda na economia & $\begin{array}{l}\text { Elevação dos preços de produtos e serviços baseado na } \\
\text { demanda turística }\end{array}$ \\
\hline & Redistribuição de renda & Excessiva dependência em relação ao turismo \\
\hline & O efeito multiplicador & $\begin{array}{l}\text { Os custos sociais e ambientais baseados na devastação } \\
\text { dos recursos naturais e culturais das regiões. }\end{array}$ \\
\hline & $\begin{array}{l}\text { Criação ou melhoria da infraestrutura das } \\
\text { localidades }\end{array}$ & $\begin{array}{l}\text { A prioridade de investimentos turísticos negligenciando } \\
\text { serviços básicos }\end{array}$ \\
\hline \multirow{5}{*}{ 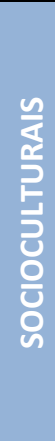 } & $\begin{array}{l}\text { Crescimento do respeito pela religião da } \\
\text { comunidade local por parte dos turistas }\end{array}$ & $\begin{array}{l}\text { Perda de espiritualidade em localidades religiosas que } \\
\text { se tornam dominadas pelos turistas }\end{array}$ \\
\hline & Renovação de formas de arte tradicionais & $\begin{array}{l}\text { Banalização/ modificação de formas de arte } \\
\text { tradicionais para satisfazer desejos de turistas }\end{array}$ \\
\hline & Conscientização de novos estilos de vida & Interferência da cultura do visitante na localidade \\
\hline & $\begin{array}{l}\text { Aspectos positivos dos comportamentos e } \\
\text { valores do turista }\end{array}$ & $\begin{array}{l}\text { Crescimento da criminalidade e; } \\
\text { Perda da dignidade por ser forçada a comportar-se de } \\
\text { maneira servil em relação aos turistas }\end{array}$ \\
\hline & Migração para comunidades periféricas & $\begin{array}{l}\text { Dominação da comunidade por imigrantes de outras } \\
\text { comunidades }\end{array}$ \\
\hline \multirow{3}{*}{$\frac{\substack{\frac{n}{c} \\
\frac{\mathrm{m}}{\mathrm{m}}}}{\sum_{<}^{\frac{0}{\alpha}}}$} & $\begin{array}{l}\text { Conscientização da importância da } \\
\text { preservação ambiental }\end{array}$ & $\begin{array}{l}\text { Contaminação das nascentes de águas pelas atividades } \\
\text { relacionadas ao turismo; Verticalização dos centros } \\
\text { urbanos impulsionados pela pressão imobiliária; } \\
\text { Transformação da paisagem }\end{array}$ \\
\hline & $\begin{array}{l}\text { Por meio das taxas cobradas, as unidades } \\
\text { de conservação podem investir em } \\
\text { infraestrutura e em treinamento de } \\
\text { recursos humanos }\end{array}$ & $\begin{array}{l}\text { Uso inadequado do solo propiciado pelos } \\
\text { empreendimentos turísticos mal planejados }\end{array}$ \\
\hline & $\begin{array}{l}\text { Valorização da natureza tanto do ponto de } \\
\text { vista econômico como paisagístico }\end{array}$ & $\begin{array}{l}\text { Transformação do espaço físico dos destinos, que } \\
\text { passam a ser orientados apenas para o turismo }\end{array}$ \\
\hline
\end{tabular}

Fonte: Dados da pesquisa baseado em Cohen (1983), Smith (1989), Swarbrooke (2000), Lage \& Milone (2001) e Lohmann \& Panosso-Netto (2012). 
Considerando as três dimensões que impactam com o advento da atividade turística em uma localidade, percebe-se que o turismo é capaz de proporcionar diversos benefícios para o local onde é desenvolvido, mas também, pode causar prejuízos se essas dimensões não forem levadas a cabo.

Portanto, deve-se pensar em planejar o turismo a partir da integração do ambiente econômico, sociocultural e ambiental, através de um resultado do desenvolvimento local e sustentável, como também é importante envolver a comunidade local nas tomadas de decisões para analisar quais impactos são causados e quais as maneiras para fazer com que sejam minimizados os negativos.

\section{Relação entre turismo e residentes e os fatores que afetam o apoio dos residentes no desenvolvimento do turismo}

Alguns estudos (Coutinho, 2016; Félix, 2018; Tsaur, Yen \& Teng, 2018) têm se dedicado a abordarem a relação entre a atitude, participação e apoio da comunidade local no processo de crescimento da atividade turística, identificando os aspectos positivos e negativos na relação entre o turista e o residente.

Neste sentido, torna-se imprescindível analisar a percepção da população local, quando se trata de desenvolvimento turístico, de forma que esta participe das tomadas de decisões expressando as suas opiniões e fornecendo sugestões para que sejam beneficiadas. Alguns destes estudos têm sido realizados no mundo, aplicando em diversas localidades, sendo estas com características semelhantes ao contexto brasileiro e outras um pouco peculiares a realidade aplicada. No entanto, o que interessa é realizar um levantamento sobre a literatura até então publicada.

Vargas-Sánchez et al. (2011), por exemplo, propuseram um modelo para ser aplicado de forma universal buscando entender a atitude do residente em relação ao desenvolvimento do turismo. O estudo realizado na Espanha identificou algumas variáveis importantes, como: comportamento dos turistas, densidade (grande fluxo) dos turistas e nível de desenvolvimento da atividade turística que é percebida pelo residente. Os resultados revelaram que os impactos positivos são mais perceptíveis do que os negativos como um importante indicativo no apoio do desenvolvimento do turismo e consequentemente uma atitude mais positiva e receptiva. A densidade dos turistas, por sua vez, sofre influência negativa, mas que consideram o desenvolvimento moderado do turismo como benéfico.

No que se refere, especificamente, ao apoio comunitário, os estudos de Gursoy et al. (2002), propuseram um modelo de relação causal para analisar o apoio comunitário no desenvolvimento do turismo. $\mathrm{O}$ estudo aplicado na realidade da América do Norte identificou que o nível de interesse dos residentes, a atitude ecocêntrica (peculiar a realidade pesquisada), a utilização de recursos de base 
local, os custos e benefícios percebidos pelos residentes com o desenvolvimento do turismo são fatores capazes de afetar o apoio dos residentes ao desenvolvimento da atividade.

No campo da psicologia, estudos semelhantes também vêm sendo desenvolvidos baseado na Teoria da Mudança Social (Social Exchange Theory - SET), por entender que a mudança que tem ocorrido no mercado e a interação social são formadas por um conjunto de intercâmbios formado por recompensas e custos que reflete no comportamento humano (Blau, 2006).

Desenvolver um modelo de análise que explique o apoio e as diversas percepções do residente no turismo está entre os objetivos da área. Neste sentido, Nunkoo e Ramkisson (2012) testaram um modelo de relacionamento de variáveis que interferem no apoio do residente, incluindo a variável confiança onde não tinha sido previamente testada nos estudos anteriores. 0 modelo resultante entende que o apoio dos residentes ao desenvolvimento do turismo é influenciado pela percepção dos benefícios e custos do turismo, na confiança nos atores governamentais, incluindo outras variáveis como o poder de influência da comunidade (Figura 01).

Figura 01. Modelo de apoio comunitário ao desenvolvimento do turismo

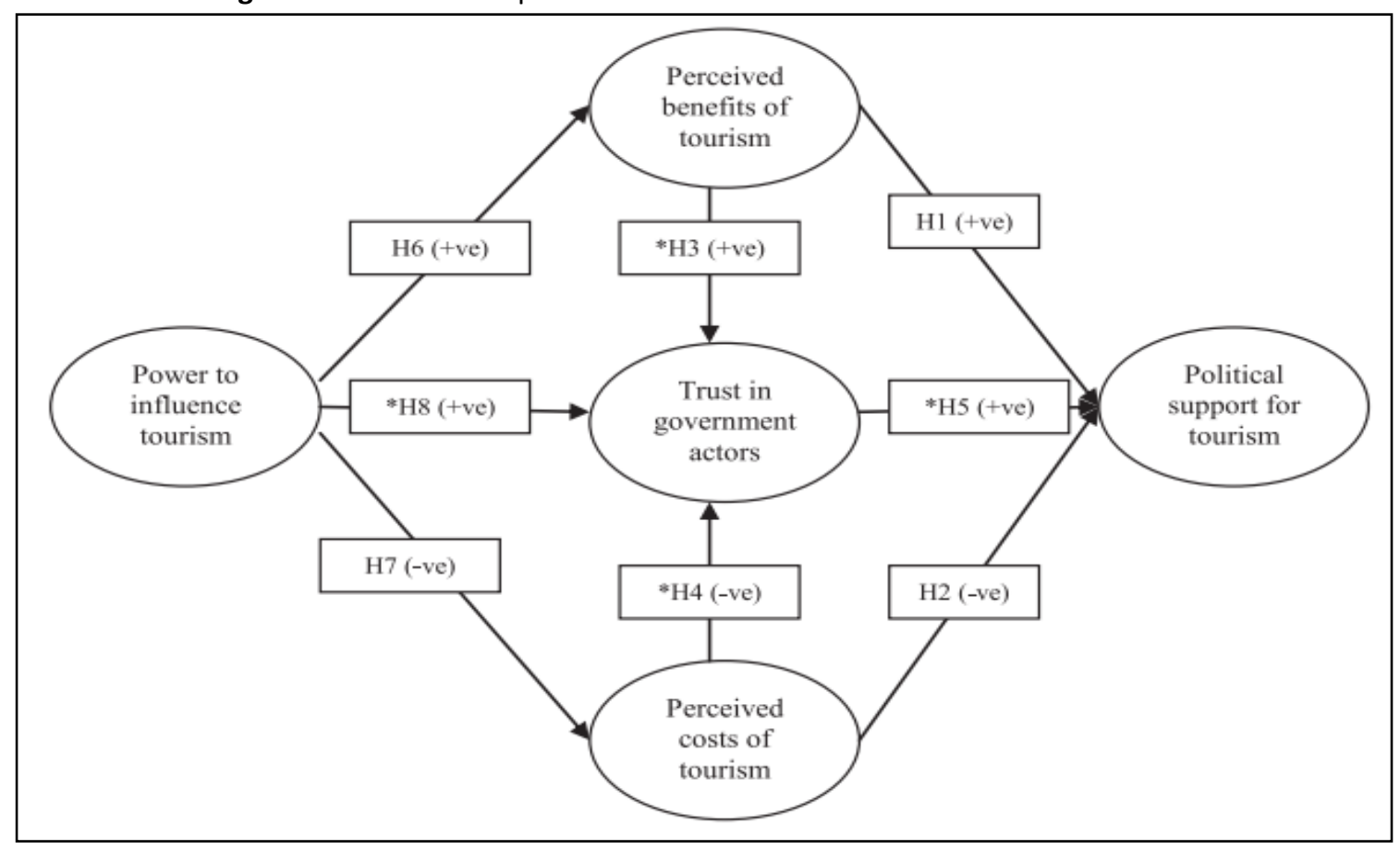

Fonte: Nunkoo \& Ramkisson (2012).

Mais recentemente, estudos como o de Milito, Marques-Júnior e Alexandre (2015), aplicados em uma capital nordestina, corroboraram com principais fatores que afetam o apoio do residente no desenvolvimento do turismo, sendo eles: compromisso da comunidade, confiança dos gestores e apego a comunidade. Estes três fatores interferem de forma variada (relação alta e 
moderada) na percepção dos benefícios e custos do turismo que são antecedentes do apoio ao desenvolvimento da atividade.

O estudo de Silva e Marques-Júnior (2016), por sua vez, aplicou um modelo de apoio do residente em uma cidade interiorana do nordeste brasileiro. O resultado da equação no estudo identificou que o apoio dos residentes é influenciado de forma direta pela percepção dos benefícios e pela confiança nos atores governamentais. De outra forma, quanto mais for perceptível os benefícios da atividade turística, maior será a confiança nos atores governamentais.

Diante das colocações, o presente estudo toma como modelo central o trabalho proposto por Nunkoo e Ramkisson (2012), demonstrado na figura 01. Entende-se, pois, que é importante identificar os fatores de apoio comunitário, promovendo ações de inclusão social através da maximização dos benefícios advindos da atividade turística.

\section{METODOLOGIA DA PESQUISA}

De acordo com autores do estudo metodológico (Martins, 2007; Oliveira, 2016), esta pesquisa é denominada como descritiva e faz uso de abordagem quantitativa. O método científico adotado é o hipotético dedutivo inspirado no positivismo lógico de Karl Popper, onde a investigação é baseada em um problema real que através do teste das hipóteses pode-se afirmar ou falsear, considerando sua experimentação (Oliveira, 2016).

Neste sentido, a pesquisa tem como objetivo testar os fatores que interferem no apoio do desenvolvimento do turismo na perspectiva dos moradores locais. O modelo teórico que será testado é proposto por Nunkoo e Ramkisson (2012) constituído por variáveis manifestas e variáveis latentes e as hipóteses testadas neste estudo são apresentadas abaixo:

- H1: O apoio do residente ao desenvolvimento do turismo é diretamente influenciado pelos benefícios econômicos gerados pela atividade turística

- H2: O apoio do residente ao desenvolvimento do turismo é diretamente influenciado pelos custos gerados pela atividade turística

- H3: A confiança nos atores governamentais influencia diretamente o apoio do residente ao desenvolvimento do turismo

- H4: O poder de influência dos empresários influencia diretamente o apoio do residente ao desenvolvimento do turismo

- H5: O apoio do residente ao desenvolvimento do turismo é influenciado quando o turismo é a principal atividade econômica 
O estudo delimitou-se à cidade de Florânia, localizado na região do Seridó, e na microrregião da Serra de Santana, a uma distância de 216 km de Natal, capital do Estado (Rio Grande do Norte, Brasil). Possui uma população estimada em 9.121 habitantes e uma área de unidade territorial de 504 km² e um Índice de Desenvolvimento Humano em 0,642 (IBGE, 2018).

O nome da cidade é atribuído devido possuir um clima ameno, que possibilita nos anos de inverno a presença de muitas flores e rosas na região. Paralelamente a estes fatores a cidade possui uma população marcadamente religiosa e mística e, portanto, seus principais atrativos estão relacionados às belezas naturais, histórico-culturais, religiosas e de eventos.

Os atrativos naturais são constituídos pelas serras, riachos, cachoeiras, mirantes, pinturas rupestres, trilhas, entre outros. Os atrativos histórico-culturais, por sua vez, são os prédios antigos que estão localizados no centro da cidade e os atrativos religiosos são identificados como o santuário de Nossa Senhora das Graças e a capela da Cruz de José Leão. Dentre os principais eventos considerados atrativos turísticos, têm-se a festa de Nossa Senhora das Graças, a Festa de São Sebastião, o Carnaval e a Festa de emancipação política.

Assim, a técnica de coleta de dados é baseada no survey, utilizando uma amostragem nãoprobabilística, por conveniência ou acidental, uma vez que as pessoas que responderam os questionários não foram pré-selecionadas. O meio de aplicação da pesquisa foi o virtual utilizando uma rede social, onde houve, previamente, uma publicação sobre a pesquisa e posteriormente era enviado o link para acessar as perguntas. Os questionários foram estruturados em uma escala métrica de 5 pontos que vai de discordo plenamente até concordo plenamente.

É importante considerar que foi realizado um pré-teste para testar as variáveis e a compreensão por parte dos pesquisados. Neste sentido, os resultados apresentados, foram com base nas análises do pré-teste e suas devidas modificações, o que explica a distinção da existência da quantidade de variáveis em cada dimensão. A pesquisa teve boa receptividade e a maioria das pessoas que foram convidadas por meio do link eletrônico, de forma acidental, aceitaram responder a pesquisa, totalizando 98 entrevistados durante o período de 02 a 15 de setembro.

Para a análise dos dados, optou-se pelo uso de ordenação e agrupamentos baseado na técnica de análise teórica, baseado nas discussões previamente apresentadas. Para isto, utilizou-se o software Statistical Package for the Social Sciences (SPSS) 22.0 para Windows, e posteriormente foram trabalhados de acordo com as especificações do objetivo a partir das análises descritivas geradas. 


\section{RESULTADOS E DISCUSSÕES}

\section{Perfil da amostra}

A amostra do estudo apresentou o gênero feminino predominante (53\%). A faixa etária se concentrou entre 21 e 30 anos (47\%) e entre 31 a 41 anos (21\%). As faixas menos representativas foram acima de 50 anos (1\%). A maioria absoluta da amostra afirmou ser solteiro com $69 \%$ dos casos, enquanto os casados representam $31 \%$ da amostra analisada. A escolaridade dos entrevistados se concentrou no ensino médio completo com $49 \%$, seguido do ensino superior completo com $22 \%$.

No que diz respeito à ocupação, 34\% dos respondentes afirmaram serem estudantes, seguida de profissional liberal (27\%), funcionário em empresa privada (17\%), desempregados (13\%) e, por último, com $9 \%$ declaram serem funcionários públicos. A renda afirmada pelos respondentes mais representativas foi de, até, um salário mínimo correspondendo a 51\% dos casos, seguida de até quatro salários mínimos (44\%).

Depreende-se que o perfil dos entrevistados está concentrado em um público feminino, com faixa etária entre 21 a 30 anos, solteiras e possuem ensino médio completo. São profissionais liberais e a renda familiar dos respondentes foi em sua maioria constituída por até 1 salário mínimo.

Estes dados supracitados revelam que o perfil constitui uma classe com uma renda baixa, com pouca escolaridade e são profissionais liberais, vislumbrando na atividade turística uma oportunidade na geração de emprego e renda em sua plena jovialidade. É um público que hipoteticamente está em busca de oportunidades sociais e por ser, em sua grande maioria jovem, estão em busca de novos desafios.

Ademais, a amostra analisada possui grande acesso à internet, uma vez que foi o meio utilizado para aplicação da pesquisa, o que pode significar que, em caso de apoio ao desenvolvimento do turismo, pode ser refletido em ações positivas e receptivas pelos meios digitais, sendo esta uma importante ferramenta de divulgação dos destinos.

\section{Percepção dos residentes sobre as dimensões estudadas}

\section{Percepção dos residentes sobre os benefícios estimulados pelo turismo}

Na Tabela 01 é possível contemplar os dados das avaliações dos respondentes sobre a dimensão dos benefícios estimulados pela atividade turística. A tabela dispõe de um total de 7 variáveis para avaliar a dimensão, com resultados positivos. 
Tabela 01. Percepção dos residentes sobre os benefícios do turismo

\begin{tabular}{|c|c|c|c|c|c|c|c|}
\hline Variáveis & 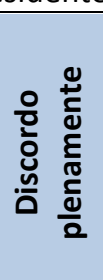 & $\begin{array}{l}\text { 운 } \\
\text { 엄 } \\
\text { 믐 }\end{array}$ & 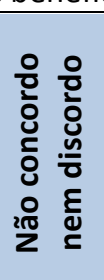 & 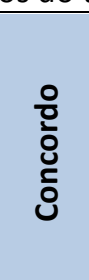 & 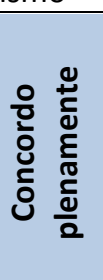 & $\frac{\pi}{\bar{c}}$ & $\begin{array}{l}\frac{0}{2 \pi} \\
\frac{\pi}{0} \\
\pi \\
\frac{0}{0} \\
\circ \\
\frac{0}{3} \\
00\end{array}$ \\
\hline $\begin{array}{l}\text { Geração de emprego para a população de } \\
\text { Florânia em decorrência do desenvolvimento } \\
\text { turístico }\end{array}$ & 0,0 & 0,0 & 9,2 & 30,6 & 60,2 & 4,51 & 0,661 \\
\hline $\begin{array}{l}\text { Aumento na renda para a população de } \\
\text { Florânia em decorrência do desenvolvimento } \\
\text { turístico }\end{array}$ & 0,0 & 0,0 & 25,5 & 31,6 & 42,9 & 4,17 & 0,812 \\
\hline $\begin{array}{l}\text { Aumento na preservação ambiental de Florânia } \\
\text { em decorrência do desenvolvimento turístico }\end{array}$ & 0,0 & 0,0 & 23,5 & 37,8 & 38,8 & 4,15 & 0,777 \\
\hline $\begin{array}{l}\text { Aumento na qualidade de vida da população } \\
\text { de Florânia em decorrência do } \\
\text { desenvolvimento turístico }\end{array}$ & 0,0 & 0,0 & 18,4 & 36,7 & 44,9 & 4,26 & 0,850 \\
\hline $\begin{array}{l}\text { Melhoria na infraestrutura da cidade de } \\
\text { Florânia em decorrência do desenvolvimento } \\
\text { turístico }\end{array}$ & 0,0 & 34,7 & 23,5 & 13,3 & 28,6 & 3,35 & 1,22 \\
\hline $\begin{array}{l}\text { Aumento no desenvolvimento de atividades } \\
\text { culturais em Florânia em decorrência do } \\
\text { desenvolvimento turístico }\end{array}$ & 3,1 & 37,8 & 32,7 & 9,2 & 17,3 & 3,00 & 0,899 \\
\hline $\begin{array}{l}\text { Aumento na valorização dos atrativos turísticos } \\
\text { em decorrência do desenvolvimento turístico }\end{array}$ & 0,0 & 0,0 & 0,0 & 42,9 & 57,1 & 4,57 & 0,497 \\
\hline
\end{tabular}

Fonte: Dados da pesquisa, 2018.

Os dados da média das avaliações dos respondentes na dimensão indicam uma elevada percepção positiva dos benefícios do turismo. Desta maneira, este pode ser um aspecto positivo sobre o apoio dos residentes no crescimento da atividade, através da geração de emprego, renda e qualidade de vida. No tocante a percepção mais ampla de desenvolvimento, tais características são limitantes na percepção dos residentes (Barquero, 2000; Boisier, 2001).

No que diz respeito a dimensão ambiental, percebe-se que é avaliada de maneira positiva pelos respondentes, confirmando a harmonia entre o processo de desenvolvimento do turismo na localidade e preservação dos recursos naturais como um tripé para a sustentabilidade do destino (Ruschmann, 2010). Por sua vez, os benefícios relacionados aos aspectos econômicos e também sociais são largamente perceptíveis, obtendo as maiores médias, o que pode contrariar alguns estudos previamente realizados no nordeste brasileiro (Silva \& Marques-Júnior, 2016; Milito, Marques-Júnior \& Alexandre, 2015).

No entanto, cabe um destaque para as variáveis infraestrutura e aumento de atividades culturais que apresentam elevados valores de desvio padrão entre as variáveis contempladas. Isto sugere que, por mais que os entrevistados possuam percepções de benefícios da atividade turística, elas ainda não são perceptíveis na localidade de forma positiva. Acredita-se que a variável infraestrutura esteja relacionado aos meios de acesso ao município e a sinalização turística que são 
elementos precários na localidade. Paralelamente a estes fatores, não há estimulo as atividades culturais da cidade que possam e estejam sendo trabalhadas pelo turismo.

\section{Percepção dos residentes sobre os custos estimulados pelo turismo}

A análise descritiva da dimensão dos custos estimulados pela atividade turística foi avaliada por meio de 5 variáveis, onde estão apresentados na tabela 02. Na mesma tabela é possível verificar dados referente a média e desvio padrão das avaliações dos respondentes sobre o constructo. É interessante observar que a dimensão 'custo do turismo' não foi apresentada com esta nomenclatura, mas avaliada por meios de suas variáveis para melhor compreensão dos entrevistados e também por compor a discussão da literatura.

Tabela 02. Percepção dos residentes sobre os custos do turismo

\begin{tabular}{|c|c|c|c|c|c|c|c|}
\hline Variáveis & 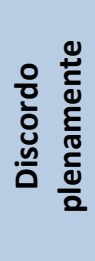 & $\begin{array}{l}\text { 윰 } \\
\text { ợ } \\
. \frac{\mathrm{n}}{0}\end{array}$ & 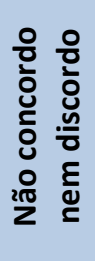 & 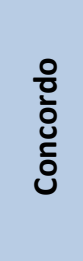 & 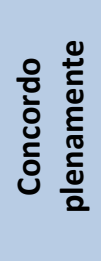 & 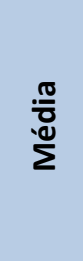 & 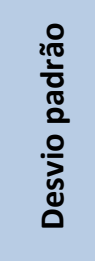 \\
\hline $\begin{array}{l}\text { Aumento nos preços de bens e serviços em } \\
\text { Florânia devido ao desenvolvimento do } \\
\text { turismo }\end{array}$ & 27,6 & 29,6 & 18,4 & 24,5 & 0,0 & 2,39 & 1,137 \\
\hline $\begin{array}{l}\text { Aumento na poluição em Florânia devido ao } \\
\text { desenvolvimento do turismo }\end{array}$ & 34,7 & 30,6 & 19,4 & 12,2 & 3,1 & 2,18 & 1,133 \\
\hline $\begin{array}{l}\text { Aumento nos problemas de trânsito em } \\
\text { Florânia devido ao desenvolvimento do } \\
\text { turismo }\end{array}$ & 32,7 & 33,7 & 24,5 & 3,1 & 6,1 & 2,16 & 1,109 \\
\hline $\begin{array}{l}\text { Aumento na prostituição em Florânia devido } \\
\text { ao desenvolvimento do turismo }\end{array}$ & 5,1 & 24,5 & 23,5 & 25,5 & 21,4 & 3,33 & 1,209 \\
\hline $\begin{array}{l}\text { Aumento na criminalidade em Florânia devido } \\
\text { ao desenvolvimento do turismo }\end{array}$ & 34,7 & 29,6 & 23,5 & 8,2 & 4,1 & 2,17 & 1,121 \\
\hline
\end{tabular}

Fonte: Dados da pesquisa, 2018.

De acordo com a Tabela 02, verifica-se que as médias das respostas são relativamente baixas, considerando que os custos ainda não são perceptíveis pelos residentes. Este fator pode estar relacionado ao fato de que o fluxo turístico na cidade ainda ser incipiente, sendo classificado pelo Ministério do Turismo na categoria $D$, como elevadas taxas de permanência em períodos sazonais, portanto, os custos não são claramente perceptíveis pelos residentes e/ou não existem.

As mudanças no estilo de vida, nos hábitos e costumes locais não foram afetadas de forma significativa com o advento do turismo, o que confirma alguns estudos na literatura (Cohen, 1983; Smith, 1989) Há que considerar, no entanto, que os custos, em muitos casos, são minimizados pelos inúmeros benefícios advindos da atividade turística que foram retratados no tópico anterior de forma significativa e, que podem ser o retrato do perfil analisado que está mais propenso as 
oportunidades econômicas e sociais, sem se importar, em muitos casos, com os custos do advindo do turismo (Silva \& Marques-Júnior, 2016; Felix; Chagas; Marques-Júnior \& Silva, 2017).

Cabe ressaltar que, somente em uma variável foi perceptível os custos - no quesito aumento da prostituição, com elevada média dos respondentes. Ainda assim, percebe-se que é uma média muito baixa, perante as demais que foram analisadas em algumas dimensões. Os demais problemas sociais, como aumento da criminalidade e problemas econômicos como aumento do preço tiveram as menores médias, indicando elevada apoio dos residentes no desenvolvimento do turismo.

\section{Percepção dos residentes sobre o poder de influência dos diversos entes no desenvolvimento do turismo}

$\mathrm{Na}$ análise do poder de influência que os diversos entes possuem no desenvolvimento do turismo, são considerados, inclusive, o poder da comunidade, permitindo realizar uma autoanálise sobre o papel da comunidade neste processo de desenvolvimento. Para esta dimensão, foram exploradas 3 variáveis que estão sinalizadas na tabela 03.

Tabela 03. Percepção dos residentes sobre o poder de influência no desenvolvimento do turismo

\begin{tabular}{|c|c|c|c|c|c|c|c|}
\hline Variáveis & 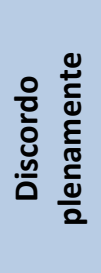 & $\begin{array}{l}\text { 음 } \\
\frac{\text { 음 }}{0}\end{array}$ & 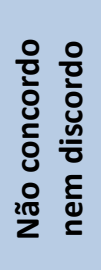 & 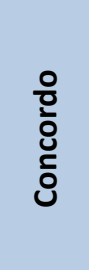 & 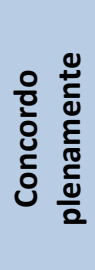 & $\stackrel{\frac{\pi}{0}}{\stackrel{0}{0}}$ & $\begin{array}{l}\frac{0}{2 \pi} \\
\frac{20}{0} \\
\frac{\pi}{0} \\
\frac{0}{0} \\
0 \\
\frac{0}{3} \\
\frac{1}{0}\end{array}$ \\
\hline $\begin{array}{l}\text { Poder de influência que a comunidade (me } \\
\text { incluindo) para o desenvolvimento do turismo } \\
\text { em Florânia }\end{array}$ & 0,0 & 23,5 & 25,5 & 45,9 & 5,1 & 3,32 & 0,894 \\
\hline $\begin{array}{l}\text { Poder de influência que os empresários do } \\
\text { turismo têm no desenvolvimento do turismo } \\
\text { em Florânia }\end{array}$ & 2,0 & 10,2 & 14,3 & 21,4 & 52,0 & 4,11 & 1,120 \\
\hline $\begin{array}{l}\text { Poder de influência que o setor público tem no } \\
\text { desenvolvimento do turismo em Florânia }\end{array}$ & 1,0 & 9,2 & 7,1 & 30,6 & 52,0 & 4,23 & 1,003 \\
\hline
\end{tabular}

Fonte: Dados da pesquisa, 2018.

Ao considerar os valores referentes as médias das variáveis, os resultados revelam um forte poder de atuação no desenvolvimento do turismo relacionado ao setor privado e público, e com média avaliação dos respondentes no poder de influência da comunidade local. As duas variáveis de maior peso confirmam o poder hegemônico sinalizado em alguns trabalhos (Coutinho, 2016; Silva \& Marques-Júnior, 2016), que atuam de forma incisiva no crescimento da atividade turística. Isto revela que, embora se tenha aberto espaços de diálogo e participação por meio de políticas públicas como criação de conselhos gestores, a comunidade pouco tem poder de decisão no processo de desenvolvimento turístico. 
Com isso, o desenvolvimento local autêntico e libertário fica comprometido, uma vez que a participação da comunidade é considerada sine qua non para este processo. A comunidade não atua de forma direta, e permanece como mero espectador as ações do poder hegemônico, restringindose as oportunidades de empregos e acesso a renda que são gerados. O empoderamento, a participação e engajamento são deixados de lado. Estes resultados confrontam as teorias de desenvolvimento aportadas na pesquisa (Boisier, 2000; Barquero, 2001; Sen, 2000). Ademais, a compreensão do poder comunitário nas decisões de desenvolvimento do turismo é antecedente influenciador direto à atitude de apoio ao referido fenômeno social (Milito, Marques-Júnior \& Alexandre, 2015; Nunkoo \& Ramkisson, 2012).

\section{Percepção dos residentes sobre a confiança nos atores governamentais}

Na Tabela 04 foi explorado a percepção dos residentes nas dimensões sobre a confiança nos atores governamentais, representando 4 variáveis. Com base nas médias dos fatores da referida tabela, seus dados apontaram percepção mediana dos respondentes sobre o nível de confiança nos atores governamentais.

Tabela 04. Percepção dos residentes sobre a confiança nos atores governamentais no desenvolvimento do turismo

\begin{tabular}{|c|c|c|c|c|c|c|c|}
\hline Variáveis & 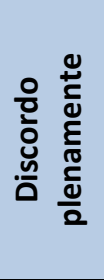 & \begin{tabular}{l}
$\circ$ \\
$\frac{0}{0}$ \\
$\stackrel{0}{0}$ \\
\hdashline 0
\end{tabular} & 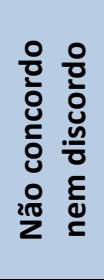 & 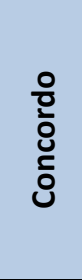 & 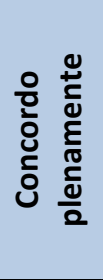 & $\frac{\pi}{\frac{\pi}{0}}$ & $\begin{array}{l}\frac{0}{20} \\
\frac{\pi}{5} \\
\frac{\pi}{2} \\
\frac{0}{2} \\
\frac{0}{3} \\
0\end{array}$ \\
\hline $\begin{array}{l}\text { Confiança da comunidade residente na } \\
\text { Prefeitura Municipal de Florânia para o } \\
\text { desenvolvimento do turismo }\end{array}$ & 4,1 & 9,2 & 21,4 & 30,6 & 34,7 & 3,82 & 1,130 \\
\hline $\begin{array}{l}\text { Confiança da comunidade residente na } \\
\text { Secretaria de Turismo municipal de Florânia } \\
\text { para o desenvolvimento do turismo }\end{array}$ & 19,4 & 30,6 & 29,6 & 14,3 & 6,1 & 2,70 & 1,613 \\
\hline $\begin{array}{l}\text { Confiança da comunidade residente na } \\
\text { Secretaria de Turismo do estado para o } \\
\text { desenvolvimento do turismo }\end{array}$ & 11,2 & 23,5 & 32,7 & 28,6 & 4,1 & 3,00 & 1,533 \\
\hline $\begin{array}{l}\text { Confiança da comunidade residente no } \\
\text { Governo Federal para o desenvolvimento do } \\
\text { turismo }\end{array}$ & 4,1 & 11,2 & 25,5 & 23,5 & 35,7 & 3,75 & 1,175 \\
\hline
\end{tabular}

Fonte: Dados da pesquisa, 2018.

Na análise descritiva da dimensão, com base na média das quatro variáveis, percebe-se que há certo nível de confiança nos atores governamentais em seus diversos níveis (local, regional e nacional). Entretanto, cabe salientar que os valores de desvio padrão presentes na tabela confirmam notória oscilação entre os atores governamentais locais, dividido nas variáveis: secretaria municipal de turismo e prefeitura, onde, neste último, há uma percepção mais elevada de confiança, ao passo 
que a secretária que está diretamente encarregada no desenvolvimento do turismo apresentou média confiança dos residentes.

Paralelamente a estes dados, observou-se que o ator governamental denominado Governo Federal recebeu uma elevada percepção de confiança apesar de estar entre os níveis o mais distante, mas que suas ações na cidade são claramente perceptíveis. Isto pode estar relacionado com a atuação deste setor nos últimos anos, através de inúmeros investimentos em educação, serviços básicos de infraestrutura, vulnerabilidade social, dentre outros aspectos. Tal percepção não foi, notoriamente, percebida pelo ator governamental regional, que recebeu um valor mediano na percepção. Isto indica que, por mais que seja elevada a variação de respostas, a percepção na confiança governamental pode variar nas suas mais diversas escalas.

O processo de desenvolvimento libertário através das discussões do desenvolvimento como liberdade deve ser regida por uma transparência das ações e poder de decisão. Deste modo, os resultados no tocante a confiança nos atores governamentais pode refutar a ideia da teoria discutida (Sen, 2000).

\section{Percepção de apoio dos residentes ao desenvolvimento do turismo}

Na Tabela 05 estão presentes os dados da dimensão de apoio ao turismo, nela foram exploradas 4 variáveis. De acordo com a média obtida das respostas, percebe-se uma média intenção de apoio dos respondentes ao desenvolvimento do turismo na cidade.

Tabela 05. Percepção do apoio dos residentes ao desenvolvimento do turismo.

\begin{tabular}{|c|c|c|c|c|c|c|c|}
\hline Variáveis & 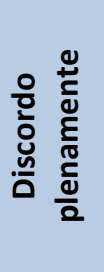 & 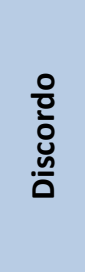 & 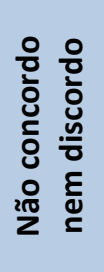 & 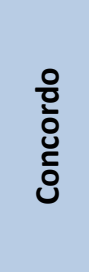 & 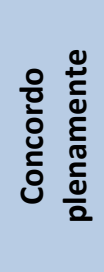 & 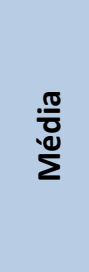 & 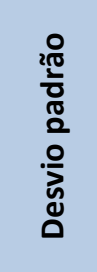 \\
\hline $\begin{array}{l}\text { O turismo é o setor mais importante da cidade } \\
\text { de Florânia/RN }\end{array}$ & 0,0 & 28,6 & 31,6 & 20,4 & 19,4 & 3,30 & 1,087 \\
\hline $\begin{array}{l}\text { O turismo ajuda no crescimento econômico da } \\
\text { cidade de Florânia/RN }\end{array}$ & 3,1 & 19,4 & 24,5 & 22,4 & 30,6 & 3,58 & 1,200 \\
\hline $\begin{array}{l}\text { O turismo possui um importante papel no } \\
\text { desenvolvimento econômico local na cidade de } \\
\text { Florânia/RN }\end{array}$ & 4,1 & 11,2 & 24,5 & 37,8 & 22,4 & 3,63 & 1,078 \\
\hline $\begin{array}{l}\text { Os turistas têm orgulho de visitar a cidade de } \\
\text { Florânia/RN }\end{array}$ & 3,1 & 2,0 & 13,3 & 27,6 & 54,1 & 4,27 & 0,982 \\
\hline
\end{tabular}

Fonte: Dados da pesquisa, 2018.

Há um notório sentimento de satisfação de pertencer a localidade o que reflete na percepção dos moradores em relação ao orgulho que os turistas têm de visitar a cidade. Todavia, as demais médias indicaram menor consenso sobre a atividade turística ser um setor em plena 
expansão na localidade e que, portanto, pode propiciar o desenvolvimento da localidade. Isto pode estar associado ao fato de que a atividade ainda não possui caráter em expansão.

Ao considerar o conjunto da percepção dos residentes em relação ao processo de desenvolvimento turístico, revela uma baixa participação social, forte percepção dos benefícios econômicos e sociais em contraposição aos custos percebidos devido ao advento da atividade turística. Com isso, as teorias de desenvolvimento turístico aportadas pela participação, existência de entorno inovador e processo libertário ficam comprometidas (Coutinho, 2016; Molina, 2003; Boyer, 2003). Entende-se que, os residentes estarão mais propensos a apoiar o desenvolvimento da atividade quanto maior for o orgulho dos turistas em visitarem a região, principalmente pelos benefícios econômicos e consequentemente sociais que trazem consigo.

Paralelamente aos resultados auferidos nesta pesquisa, é possível pensar em um processo de desenvolvimento da atividade turística na localidade pautada em maiores oportunidades sociais que possa salvaguardar os hábitos e costumes da localidade, maximizando os benefícios para além dos aspectos econômicos, mas também ambiental e sociocultural. Um desenvolvimento onde a comunidade possa ser protagonista das suas decisões proporcionada por um entorno inovador e dotados de liberdade instrumental e constitutiva, e possa deixar de lado a visão de dependência do turista e que o orgulho de pertença a localidade não seja devido a uma visão externa (Ruschmann, 2010; Sen, 2000; Boisier, 2000; Barquero, 2001; Boyer, 2003; Smith, 1989).

\section{Teste de hipóteses}

De acordo com as análises descritivas geradas, as que apresentaram valores de média baixa obtiveram correlação negativa com a dimensão analisada. Assim, das 5 hipóteses testadas, 3 se confirmaram e apenas duas foram negadas.

A hipótese 1 afirma-se que o apoio do residente ao desenvolvimento do turismo é diretamente influenciado pelos benefícios econômicos gerados pela atividade turística e foi confirmada pelos valores das médias altas nas variáveis relacionadas aos fatores econômicos como emprego, renda e qualidade de vida. No entanto, percebe-se que não somente os fatores econômicos influenciam no apoio do residente ao desenvolvimento do turismo, os benefícios ambientais e culturais também são fatores que devem ser levados em consideração no desenvolvimento da atividade na cidade de Florânia, ainda que em menor proporção. Tais resultados da pesquisa podem sinalizar uma confirmação parcial da teoria da percepção da atividade para além dos fatores econômicos (Boisier, 2000; Barquero, 2001; Ruschmann, 2010; Swarborooke, 2000; Cohen, 1983; Smith, 1989). 
A hipótese 2 afirma que o apoio do residente ao desenvolvimento do turismo é diretamente influenciado pelos custos gerados pela atividade turística e foi negada, uma vez que somente uma variável dentro da dimensão foi confirmada como percebida como custos na localidade relacionada a prostituição, mas que outros elementos como aumento dos preços dos bens e serviços, criminalidade e poluição foram negados como perceptível os custos gerados pela atividade (Cohen, 1983; Smith, 1989). Isto significa que os custos são minimizados de acordo com os benefícios percebidos na localidade, confirmando outras teorias na área (Silva \& Marques Júnior, 2016; Milito, Marques Júnior \& Alexandre, 2015). É importante considerar, no entanto, que os benefícios foram perceptíveis para além dos aspectos econômicos e isto reflete na percepção dos custos advindos da atividade turística.

A hipótese 3 afirma que a confiança nos atores governamentais influencia diretamente o apoio do residente ao desenvolvimento do turismo e foi confirmada embora não tenha resultados das médias significados, com oscilação entre as representações: locais, regionais e nacional. No entanto, há uma notória confiança no setor público e isto é um elemento de apoio ao desenvolvimento do turismo (Farias, 2013; Coutinho, 2016).

A hipótese 4 afirma que o poder de influência dos empresários influencia diretamente o apoio do residente ao desenvolvimento do turismo e foi devidamente confirmada com médias altas. A comunidade confia e percebe o desenvolvimento do turismo a partir da ação do empresariado que refletirá em outros benefícios para a localidade fazendo com que apoiem o desenvolvimento da atividade. Tal resultado da pesquisa confirma os resultados da literatura no que tange aos modelos de desenvolvimento do ciclo de vida da Área turística (Butler, 1989). É interessante observar que se o teste de hipótese estivesse alicerçado no desenvolvimento autêntico e libertário proposto pela discussão teórica, os resultados não poderiam ser plenamente confirmados por não existir uma média alta a partir do poder de influência da comunidade nos processos decisórios (Sen, 2000; Boisier, 2000; Barquero, 2001; Ruschmann, 2010)

Por fim, a hipótese 5 afirma que o apoio do residente ao desenvolvimento do turismo é influenciado quando o turismo é a principal atividade econômica e foi negado. Apesar de a cidade não perceber o turismo como principal motor de desenvolvimento da localidade e não ter um turismo com característica massificada, os respondentes não apoiariam o seu desenvolvimento se fosse a atividade principal, confirmando a literatura existente (Félix, 2018; Tsaur, Yen \& Teng, 2018; Coutinho, 2016; Molina, 2003; Boyer, 2003). O que caracteriza o seu apoio está relacionado ao orgulho de pertencerem a localidade e dos turistas em retornarem à cidade.

Assim, percebeu-se que foram apontados vários pontos positivos e negativos no desenvolvimento do turismo em Florânia/RN e que por mais que a atividade ainda não esteja 
plenamente desenvolvida no município, os residentes possuem uma percepção positiva em relação ao turismo na localidade. Então esses pontos negativos que foram apontados servirão de base para desenvolver um planejamento turístico de acordo com os desejos e necessidades da população local.

\section{CONSIDERAÇÕES FINAIS}

Ao tomar como base o objetivo do estudo, cabe considerar que os residentes da cidade de Florânia, são influenciados em apoiar o desenvolvimento do turismo pelo orgulho que os turistas têm de visitar a localidade e, consequentemente reflete o sentimento de satisfação de pertença dos residentes. Considera-se, ainda, como fatores de apoio ao desenvolvimento da atividade a percepção dos benefícios para além dos fatores econômicos e forte apoio e confiança nos atores governamentais e no empresariado e. Custos advindos da atividade turística devem ser minimizados para obter um maior apoio dos residentes.

Dos avanços obtidos na pesquisa que permitam uma generalização de um modelo geral se observa que das 5 hipóteses centrais, 3 foram confirmadas (Hipótese 1, 3 e 4), reafirmando a escolha teórica da pesquisa. No entanto, duas hipóteses foram negadas (Hipóteses 2 e 5) na realidade investigada, reforçando a necessidade de um estudo em toda a região para confirmar dados mais robustos.

É importante considerar que, na localidade investigada, o turismo não é a principal atividade e, portanto, não está em fase de consolidação, mas há práticas pontuais que permitiram sua avaliação por parte dos respondentes, portanto, estudos mais aprofundados com o objetivo de entender o comportamento dos residentes, bem como o desenvolvimento da atividade, devem ser incentivados. Ademais, estudos de avaliação da relação entre turistas e residentes devem ser reforçados em localidades onde esteja em processo de inicialização que permitam ações estruturadoras de planejamento na localidade.

O estudo permitiu a compreensão sobre a percepção de localidades fora do grande eixo central do turismo brasileiro, com o enfoque na comunidade local. A partir dos resultados obtidos, entende-se que os grupos opositores ao desenvolvimento do turismo na localidade podem ser minimizados, permitindo a maximização dos benefícios.

Constitui como limitação do estudo uma análise das principais literaturas internacionais em realidades semelhantes, aprofundando valores como poder de influência e confiança nos atores governamentais onde podem ser identificadas percepções diferenciadas e similitudes com a presente investigação e delinear um modelo de proposta específica. Também se deve aprofundar nos modelos de análises existentes, podendo incluir, por exemplo, análise de regressão para saber o poder de influência de um fator na variável "Apoio". No que se refere à realidade investigada, 
incentiva-se estudos nesta perspectiva abrangendo a região como um todo a partir da identificação de segmentos semelhantes e onde possa ser pensado o turismo a partir da ótica do residente.

\section{REFERÊNCIAS}

Barquero, A. V. (2001). Desenvolvimento Endógeno em Tempos de Globalização. Porto Alegre: Fundação de Economia e Estatística.

Blau, P. M. (2006). Exchange and Power in Social Life. Wiley, New York.

Beni, M. C. (2006). Política e planejamento do turismo no Brasil. São Paulo, Aleph.

Boisier, S. (2000). Desarrollo (Local): De qué estamos hablando? In: Becker, D. F., \& Bandeira, P. S. Desenvolvimento Local e Regional: Determinantes e Desafíos Contemporáneos. Santa Cruz Do Sul: Edunisc.

Boyer, M. (2003). História do turismo de massa. Bauru: EDUSC.

Butler, R. W. (1980). The Concept of a Tourist Area Cycle Of Evolution: Implications For Management Of Resources. The Canadian Geographer, Xxiv (I), 5-12. Recuperado de Http://Www.Numptynerd.Net/Uploads/1/2/0/6/12061984/Butler_Model_1980.Pdf

Coutinho, A. C. A. (2016) Concepção do estado das novas institucionalidades políticas: como isto reflete nas instâncias de governança em turismo? O caso do conselho estadual de turismo do Rio Grande do Norte. Turydes (Málaga), 9 (15).

Cohen, E. (1983). The sociology of tourism. Jerusalém, The Hebrew University.

Farias, M. F. Turismo Religioso na Cidade da Santa: A Percepção Da Comunidade Sobre A Construção do Complexo Turístico de Religioso Alto de Santa Rita, Santa Cruz/RN. 2013. 180 f. Dissertação (Mestrado em Turismo) - Centro De Ciências Sociais Aplicadas, Universidade Federal do Rio Grande do Norte, Natal, 2013.

Felix, J. P. S. (2018). Análise das Relações entre o Apoio dos Residentes ao desenvolvimento do Turismo nas Comunidades Indígenas e Quilombola da Microrregião do Litoral Sul e Seus Antecedentes. Canguaretama, RN. Monografia - Instituto Federal de Educação, Ciência e Tecnologia do Rio Grande do Norte.

Gursoy, D. \& Rutherford, D. (2004) Host Attitudes Toward Tourism: An Improved Structural Model. Annals Of Tourism Research 31(3): 495-516

Lage, B. H.C., \& Milone, P. C. (2001) Economia do Turismo. São Paulo: Atlas, (7).

Leiper, N. (1979) The Framework Of Tourism: Towards A Definition Of Tourism, Tourist, And The Tourist Industry. Annals Of Tourism Research 6 (4): 390-407

Lohmann, G., Panosso-Netto, A. (2012) Teoria do Turismo: Conceitos, Modelos e Sistemas. São Paulo: Aleph.

Molina, S. (2003). O pós-turismo. São Paulo: Aleph (Série Turismo).

Moreira, S. B., \& Crespo, N. (2012). Economia do Desenvolvimento: das abordagens tradicionais aos novos conceitos de desenvolvimento. Revista de Economia, 36 (2), 25- 50. 
Mccool, S., Butler, R., Buckley, R., Weaver, \& D., Wheeller, B. (2013). Is Concept Of Sustainability Utopian: Ideally Perfect But Impracticable? Tourism Recreation Research. 38 (2): 213-242.

Milito, M. C., Marques-Júnior, S., \& Alexandre, M L. (2015). Factores que influyen en el apoyo que los residentes dan a los mega eventos: Un estudio sobre la Fifa World Cup 2014 (Natal / RN Brasil). Estudios y Perspectivas en Turismo, 24(1), 153-171.

Moraes, E. A., Irving, M.; \& Mendonça, T. (2018). Turismo de base comunitária na América Latina: uma estratégia em rede. Turismo. Visão $e$ Ação, 20 (2), 249-265. http://dx.doi.org/10.14210/rtva.v20n2.p249-265

Nunkoo, R.; Ramkisson, H. \& Gursoy, D. (2012) Public Trust In Tourism Institutions. Annals Of Tourism Research. 39(3), 1538-1564

Nunes, M., \& Menezes, M. (2018). Turismo de Base Comunitária: a reconstrução de identidades desde a experiência do encontro. Revista Cenário, 5(9), 96-108. https://doi.org/10.26512/revistacenario.v5i9.19441

Oliveira, M. M. (2016). Como fazer pesquisa qualitativa: 7 Ed. Petrópolis, Vozes.

Pirilo, S., \& Cerdan, L. (2010). Turismo, Políticas e Desenvolvimento Humano. Porto Alegre: Asterisco.

Ruschmann, D. (2010). Gestão Ambiental e Sustentabilidade no Turismo. São Paulo: Manole.

Seers, D. (1970) The Meaning Of Development. Revista Brasileira De Economia, 24 (3), Fundação Getulio Vargas: Rio De Janeiro.

Silva, G. B.; \& Marques-Júnior, S. (2016). Fatores que afetam o apoio dos residentes para o desenvolvimento do turismo religioso: O caso de Santa Cruz (RN). Brasil. Rev. Bras. Pesq. Tur. São Paulo, 10(3), 497-515. Doi: Http://Dx.Doi.Org/10.7784/Rbtur.V10i3.957

Smith, V. (1989). Host and Guests: the antropology of tourism. Philadelphia, University of Pensylvania Press.

Sen, A. (2000) Desenvolvimento como Liberdade. São Paulo: Companhia das Letras.

Swarbrooke, J. (2000) Turismo Sustentável: conceitos e impacto ambiental. São Paulo: Aleph.

Tomazzoni, E. L. (2009) Turismo e Desenvolvimento Regional: dimensões, elementos e indicadores. Caxias do Sul, RS: Educs.

Tomazin, M., \& Beni, M. C. (2017). Limites e possibilidades da inclusão social pela Política Nacional de Turismo: $O$ caso do Programa de Regionalização do Turismo. Revista Cenário, 5 (8). Recuperado de http://periodicos.unb.br/ojs311/index.php/revistacenario/article/view/15053

Tsaur, S. H.; Yen, C. H. \& Teng, H. Y. (2018). Tourist-Resident Conflict: A Scale Development And Empirical Study. Journal of Destination Marketing \& Management. 10: 152-163. Dói: https://Doi.Org/10.1016/J.Jdmm.2018.09.002

Urano, D. et al. (2015). Turismo e Desenvolvimento em Comunidades Litorâneas do Nordeste Brasileiro: Os Casos de Canoa Quebrada, CE, e Maracajaú, RN. Revista Rosa dos Ventos. 7 (4), pp. 574-590. Dói: http://dx.doi.org/10.18226/21789061.v7iss4p574.

Vargas-Sanchez, A., Porras-Bueno, N., \& Plaza-Mejía, M. A. (2011). Explaining Residents' Attitudes To Tourism Is A Universal Model Possible? Annals of Tourism Research. 38(2):460-480. 